\title{
Risk factors and outcomes of urinary tract infections after pediatric renal transplant
}

\author{
Kaan Gulleroglu ${ }^{1}$, Esra Baskin ${ }^{1}$, Aysun C. Yilmaz ${ }^{1}$, Aydincan Akdur ${ }^{2}$, Gokhan Moray ${ }^{2}$, Mehmet Haberal ${ }^{2}$ \\ ${ }^{1}$ Department of Pediatric Nephrology, Baskent University Hospital, Ankara, Turkey \\ ${ }^{2}$ Department of General Surgery, Baskent University Hospital, Ankara, Turkey
}

Background: Recurrent urinary tract infections are a common and important problem after renal transplant. We evaluate risk factors and outcomes of urinary tract infections after pediatric renal transplant.

Methods: We retrospectively evaluated the data files from 165 pediatric renal transplant patients. Patients with and without urinary tract infections after renal transplant were divided into two groups. Demographics of the patients, graft functions, infections, acute rejection episodes, and graft loss were recorded.

Results: One hundred sixty-five children (92 males and 73 females) with kidney transplant were enrolled to the study, 61 of them had urinary tract infection after renal transplant. Mean age at the time of the transplantation was $12.92 \pm 4.73$ years. Mean follow-up time after transplantation was $6.36 \pm 4.45$ years. Mean episode of urinary tract infection was $3.60 \pm 3.05$ episode/patient. Although urinary tract infections rate was significantly higher in patients with lower urinary tract dysfunction, $35 \%$ of patient without lower urinary tract dysfunction had urinary tract infection after renal transplant. Urinary tract infection risk was 2.58 times higher for girls when compared with boys. There was any significant difference between two groups for immunosuppressive treatment. Glomerular filtration rate (GFR) values at 3 years $(76.10 \pm 31.30 \mathrm{~mL} / \mathrm{min}$ vs. $76.74 \pm 30.20 \mathrm{~mL} / \mathrm{min} ; \mathrm{P}=0.90)$ and 5 years of follow-up $(68.43 \pm 33.50 \mathrm{~mL} / \mathrm{min}$ vs. $59.63 \pm 32.15 \mathrm{~mL} / \mathrm{min} ; \mathrm{P}=0.20)$ of two groups was similar. There was any significant difference between two groups for rejection episodes. Eight patients (4.84\%) were lost their graft during 5 years of follow-up. Three of these patients was also in urinary tract infection group and one of them has lower urinary tract dysfunction.

Conclusions: Lower urinary tract dysfunction and female gender are major risk factors for recurrent urinary tract infections after renal transplant. Renal transplant has similar outcomes, with similar GFR levels and acute rejection episode rate in children with and without urinary tract infection. Close monitoring, adequate treatment and appropriate prophylaxis of urinary tract infection will improve outcomes of renal transplant.

Corresponding author: Kaan Gulleroglu

E-mail: rectorate@baskent.edu.tr

(C) The Korean Society for Transplantation

This is an Open Access article distributed under the terms of the Creative Commons Attribution Non-Commercial License (http://creativecommons.org/licenses/by-nc/4.0/) which permits unrestricted non-commercial use, distribution, and reproduction in any medium, provided the original work is properly cited. 